\title{
O BRILHO INESPERADO DE UM DESEJO OU KAFKA, UM DESEJO INDESTRUTÍVEL
}

Bárbara Guatimosim*

RESUMO: Aos quarenta anos, Franz Kafka definha, após o que considera seu maior fracasso na vida: o fracasso amoroso, ao qual atribui sua doença. Ao mesmo tempo durante toda a vida em busca do caminho verdadeiro nesse momento, encontra em uma mulher a hora da verdade. Com Dora Diamant, Kafka não deixará a vida sem nela lançar seu ato, arrancado de todas as angústias que o paralisavam. Ato de escrita que separa e une.

PALAVRAS-CHAVE: Supereu; Escrita; Desejo; Ato; Amor
* bguatimosim@bol.com.br

Psicanalista e Mestre em Teoria da Literatura pel Faculdade de Letras da UFMG.

RÉSUMÉ: À l'âge de quarante ans, Franz Kafka dépérit après ce qu'il considère son plus grand échec de vie: l'échec amoureux, auquel en même temps il attribue la maladie de toute sa vie, à la recherche du véritable chemin. En ce moment, il trouve auprès d'une femme l'heure de la vérité. Avec Dora Diamant, il ne quittera pas la vie avant d'y réaliser son acte arraché à toutes les angoisses qui le paralysaient. Acte d'écriture qui sépare et unit.

MOT-CLÉS: Surmoi; Écriture; Désir; Acte; Amour 
1. Texto escrito a partir de um fragmento da dissertação de mestrado "Kafka e a escrita destinada ao pai: de uma Carta à letra." Defendida em $2013 \mathrm{n}$ FALE/UFMG. Kafka: parte I, s/p.

2. KAFKA, F. Diários, 04/05/1915, Difel, p. 304
Em 1919, Franz Kafka escreve uma longa Carta ao pai, um acerto de contas para o final da vida, tentando entender e explicar porque havia fracassado como filho, homem e escritor. Estamos agora em 1923. O escritor tem 40 anos. Dois noivados rompidos com Felice, uma nova tentativa de se comprometer com Julie Wöhryzek, faz ao todo a conta de três noivados fracassados. Depois de ter recebido Milena, sua tradutora para o tcheco, como um presente de amor inesperado e sofrido dolorosamente sua perda, nosso escritor coleciona fracassos, parecendo estar condenado à sua melancolia. Próximo do fim, ele é levado por uma tuberculose galopante. Mas eis que entra em cena Dora Diamant, a jovem judia polonesa que lhe surge como a tão ansiada terra prometida. Quando eu vi Kafka pela primeira vez, sua imagem correspondeu logo à ideia que eu fazia de um homem. Mas Kafka, ele também me olhou com muita atenção, como se esperasse de mim alguma coisa. ${ }^{1}$ Encontrar uma mulher não era qualquer coisa para Franz, mas algo próximo de uma redenção: "Por mais insignificante que eu seja, não há contudo aqui ninguém que me compreenda inteiramente. Ter alguém com uma tal compreensão, talvez uma esposa, significaria ter apoios de todos os lados, ter Deus."2

Os biógrafos comentam a preferência de Kafka por moças mais jovens, associando isso à sua estima especial por Ottla a irmã mais nova (em suas palavras: mãe, irmã, esposa). Mas não podemos esquecer que Kafka, mesmo com a idade de um senhor, sentia-se doente, fraco, imaturo, mal acabado como homem e que, portanto, as bem mais jovens podiam estar muito mais próximas dele e da pureza que prezava no amor do que as já então mulheres feitas. A última companheira de Kafka, Dora Diamant, tinha 19 anos quando o conheceu em 1923. Franz tinha o dobro de sua idade. Ela assim o descreve

Ele era alto e magro, caminhava a passos largos, tinha a pele escura, tanto que pensei, primeiro, que ele não fosse europeu, mas que tinha sangue indiano. Tinha por vezes o andar um pouco vacilante, mas permanecia com a postura sempre muito correta. Apenas costumava inclinar ligeiramente a cabeça, semelhante àquela atitude que o solitário constantemente tem em relação a qualquer coisa de misterioso que lhe seja exterior. Dava a impressão de estar à espreita, mas acrescentava também nesse gesto uma grande ternura que eu interprete mesmo como sendo um desejo de ir em direção aos outros, como se quisesse dizer: "Só. Eu não sou nada. Existo somente se me encontro em relação com o mundo exterior". ${ }^{3} \mathrm{Na}$ companhia de Dora, Kafka conseguiu fazer o que até então não fizera com mulher alguma: "desligou-se da família, desligou-se de Praga e foi viver com ela em Berlim. Viveram juntos, em precárias condições econômicas, mas num clima de tranquilidade íntima e felicidade." ${ }^{4}$ Franz que vivia assolado por fantasmas, diz ao amigo Brod que havia escapado deles com a
3. DIAMANT, D. Minha vida com Franz Kafka: parte I, s/p.

4. KONDER, L. Kafka vida e obra, p. 80
(E) TSE
BELO HORIZONTE

v. 19 
5. Kafka apud LEMAIRE, G-G. Kafka p. 222.

6. DIAMANT, D. Minha vida com Franz Kafka: parte III, s/p.

7. Ben-Tovim citada por LEMAIRE, G-G. Kafka, p. 224.

8. Ben-Tovim citada por PAWEL, E. O pesadelo da razão, p. 418. ida para Berlim. "Eu escapei por entre os dedos deles. Essa partida para Berlim foi magnífica, eles agora me procuram, mas não me encontram, pelo menos por enquanto,"5 Dora também foi testemunha desse desejo de nascer de novo para a vida e para a literatura: Ele não cessava de dizer: "Como eu gostaria de saber se escapei dos fantasmas!”. Com esse apelo, resumia tudo aquilo que lhe havia atormentado antes de sua chegada a Berlim [...]. Para libertar sua alma desses "fantasmas", ele queria queimar tudo aquilo que havia escrito. Eu respeitei sua vontade e, debaixo dos seus olhos, enquanto ele repousava doente, em seu leito, queimei alguns de seus textos. Aquilo que verdadeiramente gostaria de escrever, Franz faria somente depois de conquistada sua "liberdade". A literatura era qualquer coisa de sagrado para ele, de absoluto, de intocável. [... quando se tratava de literatura, ele se tornava intransigente $e$ não fazia concessões, pois era toda a sua existência que estava envolvida. ${ }^{6}$ Kafka procurava solo firme, raízes e um judaísmo mais legítimo do que tinha encontrado junto ao pai. Puah Ben-Tovim, professora de hebraico de Franz, dizia que ele queria saber tudo sobre os judeus orientais. Queria trabalhar a terra mas devido as suas condiç̃es físicas "o estudo do hebraico acabou tornando-se seu laço simbólico com a Palestina." 7

Dora, que era fluente em hebraico e em iídiche, encontrou um homem descrito pela mestra como "um afogado a debater-se, pronto a pendurar-se em quem quer que se aproximasse o bastante para que ele o agarrasse". ${ }^{8}$ Para o biógrafo
Ernest Pawel, "a presença silenciosa de Kafka, sua aparência sofrida e sua conduta grave comoveram a menina e a mãe que havia nela." Dora "não apenas se apaixonou por Kafka, como também passou a idolatrá-lo como seu professor e mestre" Por sua vez Dora, apesar de sua pouca idade, era uma mulher muito especial. Descrita como solitária, "Estrangeira em uma terra estranha" era "intransigentemente apaixonada em tudo que fazia, com uma energia equiparável à tempestuosa intensidade de suas emoções". ${ }^{10}$ Seja o que for que concorreu para a parceria que Dora e Franz sustentaram, o fato de que era Ele e era Ela fez a real diferença. Pawel decide, em última análise, que "deve ter sido a franqueza límpida de Dora" que "derrotou a conspiração das ambiguidades e permitiu que ele - com o ardoroso apoio da irmã Ottla - arriscasse um passo de coragem literalmente desafiadora da morte." ${ }^{11} \mathrm{Ou}$ segundo as palavras de Kafka: "um feito de temerária ousadia, considerando-se meu estado, cujo equivalente só se pode encontrar, revirando as páginas da história, digamos, até a invasão da Rússia por Napoleão."12

Um passo que se faz ato, antecipado de muita angústia da qual arrancou, com todas as forças, uma certeza. Descreve em carta a Ottla como foi a noite que antecedeu sua partida para a Alemanha: "a noite anterior havia sido uma das piores que jamais tive, dividida mais ou menos em três partes: primeiro, um ataque de todas as minhas angústias, e tão fortes
9. PAWEL, E. /dem, p. 418

10. PAWEL, E. Idem, p. 418

11. PAWEL, E. Idem, p. $418-419$

12. Kafka citado por PAWEL, E. Idem, p. 419 . 
13. Kafka apud LEMAIRE, G-G. Kafka, p. 220.

14. KAFKA, F. Franz Kafka: contos, fábulas e aforismos, p. 92.

15. Kafka, em Carta a Minze, março de 1920. In: KAFKA, F. Cartas aos meus amigos, p. 69 .

16. LEMAIRE, G-G. Kafka, p. 217. quanto essas angústias nenhum exército da história mundia jamais foi." 13

Em seguida, Kafka vacila em levar adiante os planos, chegando a passar boa parte da noite a redigir um telegrama cancelando a reserva do apartamento em Berlim e, ao mesmo tempo, desesperando-se por isso. Mas, enfim, consegue com ajuda da governanta fazer as malas e partir, despedindo-se dos seus pais no dia 24/09/1923. Três anos antes, entre seus aforismos, encontramos a legenda que acompanha seu ato: "A partir de certo ponto não há mais qualquer possibilidade de retorno. É exatamente esse o ponto que devemos alcançar." ${ }^{14}$ No mesmo ano, em uma carta a sua amiga Minze, chega a dizer algo que, três anos depois, cabe-lhe como nunca: "Talvez paz e lar não chegam como um presente, mas têm que ser conquistados, devem ser algo de que você possa dizer: isto é obra minha." ${ }^{15}$ Kafka descobre no coração da dívida e de todo seu sentimento de culpa, a verdadeira conta que ainda não acertara com seu desejo e que seu ato de separação e união retifica.

Porém, nessa altura dos acontecimentos, como escreve Lemaire, o fim é o começo: "Tudo parece começar para Franz Kafka durante o verão de 1923, quando na realidade tudo está a ponto de terminar."16

Podemos ainda considerar que Kafka não desconhecia a gravidade de sua situação. Em 1922, já encontramos no
Diário: "Na escrita da minha vida ainda se fazem as contas como se a minha vida só começasse amanhã. E entretanto chego ao fim". ${ }^{17} \mathrm{O}$ ato na direção da qual seu desejo sempre apontou, desde o encontro com Felice que também o chamara a Berlim, não podia ser mais procrastinado. "Berlim é o antídoto contra Praga". ${ }^{18}$ Comenta Pawel que, "àquela altura, a doença havia despojado a vida das ambiguidades e a reduzia aos elementos essenciais. ${ }^{19}$ Comentamos nós que, além de produção de sofrimento gozoso, a doença pode ter tido, em Kafka, efeitos de castração que o lançaram na via do desejo.

Segundo Blanchot, Kafka em seu vínculo com Dora, mais uma vez segue repetindo, insistindo em mais um dos noivados impossíveis, no qual se reproduz sua impotência infinita de casar-se e constituir família e de ser mais um sócio na comunidade dos homens. Pelas respostas de não autorização que recebe, parece haver uma designação pelo negativo de sua condição, no fato de estar em exclusão com relação à lei, onde paradoxalmente ele aí se reconhece, mais de uma vez, como fora da lei. O limite intransponível acaba, então, por se revelar na própria transgressão. Para Blanchot, Kafka, "em seu jogo trágico com a lei [...] provoca as provocações", insufla a não autorização; ele "se delata por alterar ou adiantar-se a toda lei"; ${ }^{20}$ o seu próprio passo revela-lhe o infranqueável. E com isso, ao final, mais uma vez, com o passo
17. KAFKA, F. Diários, 12/02/1922, Difel, p. 368.

18. PAWEL, E. O pesadelo da razão, p. 419.

19. PAWEL, E. /dem, p. 424
EM TESE

v. 19

N. 3

SET.-DEZ. 2013

GUATIMOSIM. 0 brilho inesperado de um desejo [...] P. $54-60$
20. BLANCHOT, M. “La palabra postrera". In: BLANCHOT, M. De Kafka a Kafka, p. 324. 
21. Para entender o que aqui está em jogo é preciso distinguir mora e ética como faz Lacan. Logo no início de seu Livro 7, lemos: "Falando de ética da psicanálise escolhi uma palavra que não me parece por acaso. Moral, poderia ainda ter dito. Se digo ética, verão por quê, não é pelo prazer de utilizar um termo mais raro." $O$ seminário: a ética da psicanálise, p. 10.

22. BLANCHOT, M. “La palabra postrera". In: BLANCHOT, M. De Kafka a Kafka, p. 324 (Na literatura sobre Kafka encontramos o sobrenome de Dora escrito Diamant e também Dymant) transgressivo de sua fuga com Dora, ele chama pela interdição, pela lei, com seu quarto pedido de casamento, resposta que lhe vem, dias antes de morrer, pelo "não" do pai de Dora. Eis a questão que orienta as reflexões de Blanchot, que parece entender aqui a lei em um sentido moral: ${ }^{21}$ "Não deixa de surpreender-nos que, inclusive antes que o matrimônio com Dora Dymant seja recusado pelo conselho supremo, Kafka faça caso omisso e, opondo-se às conveniências sociais, ajeite com a adolescente uma espécie de vida comum."22

Porém, considerando os efeitos do mandamento supereuoico que incidem no caso de Kafka, a dita e suposta "transgressão" pede também a leitura a partir de uma contextualização primada por uma prudência específica: o tipo de relação de Kafka com a lei (leis), o Outro (outros) e autoridade. Kafka se via fora da lei do pai, com parcos recursos simbólicos, e, por isso mesmo, precisava obedecer tanto esperando do outro não só autorização de seus atos, mas até mesmo a confirmação de sua existência. Por toda sua vida, Kafka buscou uma fuga e uma saída agarrando-se à literatura, à escrita de cartas, aos seus Diários.

Além da contingência de encontros reais, como o que aconteceu com Dora, o enfrentamento com o supereu para um sujeito exige o tempo de muitas repetições. Lacan nos diz aqui como se trata a instância que paralisa o desejo: trazendo cem vezes ao tear nosso trabalho, o sujeito, confessando a sua história na primeira pessoa, progride na ordem das relações simbólicas fundamentais em que tem de encontrar o tempo, resolvendo as paradas e as inibições que constituem o supereu. É preciso o tempo. ${ }^{23}$ Depois de tanto testemunhar sua dor, investigar e tratar seus impasses por escrito, alguma coisa da ordem de um trabalho analítico parece ter se processado em Kafka. "A rabiscação (Durch das Gekritzel) [garatuja] me serve para fugir diante de mim mesmo, mas no ponto final (Schlußpunkt) eu me alcanço. Não posso escapar a mim mesmo." ${ }^{24}$

Temos então um Tour de Force sobredeterminado. Em 1923, aos 40 anos, Franz Kafka ainda carrega o "mérito" de ser um funcionário padrão e exemplar; Franz, o obedientíssimo, aposenta-se e, pela primeira vez em toda sua vida, arrancando do íntimo a justeza e justiça de outra lei, a lei ética do desejo, se faz homem: ele escolhe uma mulher. Para fazer valer seu ato, não somente não pede autorização aos pais, como também resiste a todas as objeções da família, partindo com convicção ao encontro de sua companheira. Dora, por sua vez, apesar de não ter rompido com os pais, tinha abandonado a Polônia e a vida judaica tradicional que a constrangia, em busca de liberdade e independência. Ao conhecer Kafka, decidiu ir com ele para uma nova vida em Berlim. Por uma única vez Kafka não esperou do Outro a autorização para unir-se a uma mulher e agir como homem em nome próprio. Em Berlim, Kafka,
23. LACAN, J. Livro 1 - o seminário os escritos técnicos de Freud, $p$. 323.

24. JANOUCHE, G. Conversas com Kafka, p.222.
EM TESE

BELO HORIZONTE

v. 19

N. 3

SET.-DEZ. 2013

GUATIMOSIM. 0 brilho inesperado de um desejo [...]

P. $54-60$ 
25. Kafka apud BROD, M. Franz Kafka, p. 184.

26. DIAMANT, D. Minha vida com Franz Kafka: parte III, s/p.

27. Kafka apud PAWEL, E. $O$ pesadelo da razão, p. 425. levando uma vida espartana para não perder sua liberdade tão duramente conquistada e não cair novamente na dependência familiar, passa a escrever com mais frequência e entusiasmo, chegando mesmo a vender alguns contos para publicação Pensava também em liquidar com isso "dívidas familiares". Entre esses contos, estão "Uma pequena mulher", "Josefina, a cantora" e "O covil" [A toca, A construção]:

"A construção" foi escrita em uma única noite, durante o inverno; ele começou no início da noite e terminou ao amanhecer, antes de retrabalhá-la por completo. Ele me contou a história, alternando o tom de gracejo com um tom mais sério [...] O sentimento de medo e pânico presente nela talvez tenha sido provocado por um pressentimento de retorno aos seus familiares bem como do fim de sua liberdade. Ele me explicou que, em sua "construção", eu seria o "coração da cidadela" ${ }^{26}$

Nessa época, Kafka frequenta como aluno, gratuitamente, a Academia Berlinense da Ciência do Judaísmo onde encontra "um oásis de paz na violenta Berlim e nas regiões turbulentas do eu interior" ${ }^{\prime 7}$ e pensa em ingressar numa escola de jardinagem brincando com a ideia de fazer o deserto florescer. Já que o deserto que o ocupa não apresenta saída possível, o desejo insiste na utopia de habitá-lo. Quem sabe transformar o deserto em terra prometida: uma última metamorfose..
Apesar do clima da vida tranquila, sem insônia e quase feliz, a doença se agrava e a ameaça dos fantasmas permanece. Kafka, quando mais jovem, imaginava morrer com satisfação e, depois do fracasso do terceiro noivado, já esperava impacientemente pela morte. "Por que tantas paradas na estrada para a morte? Por que leva tanto tempo?" ${ }^{28}$ Com uma tuberculose que avançava do pulmão até à laringe, tardiamente, descobre, com Dora, uma razão para buscar a saúde e lutar ardentemente pela vida. Comenta Leandro Konder que, "Surpreendentemente, não foi a literatura que lhe proporcionou a alegria vivida no último ano e sim o amor. Até sua morte, Franz teve dúvidas quanto a validade do que havia escrito." 29

Porém, mesmo com a saúde precária e a despeito das dificuldades de toda ordem em manter a nova vida com Dora, Kafka, no último ano de vida, sem poder beber ou se alimentar, corrige ainda e incansavelmente as provas d'O artista da fome, pouco antes de sustar a pena definitivamente. Kafka, com todo fracasso que carregava, nunca desistiu de amar e de escrever. Mesmo com todo sentimento de nulidade que nutria por si, sempre esperou e lutou pelo amor de uma mulher e pela literatura.

\section{REFERÊNCIAS}

BROD, Max. Franz Kafka.Tradução Susana Schnitzer da Silva. Lisboa: Odisseia, [s.d.].
28. Kafka em lamento a Brod apud PAWEL, E. Idem, p. 370.

29. KONDER, L. Kafka, p. 19 
BLANCHOT, Maurice. De Kafka a Kafka. Tradução Jorge Ferreiro. Mexico: Fondo de Cultura Econômica, 1991.

JANOUCH, Gustav. Conversas com Kafka: (1968). Tradução Celina Luz. Rio de Janeiro: Nova fronteira, 1983.

KAFKA, Franz. Diários. Tradução Maria Adélia Silva Melo. Algés, Portugal: Difel, 2002

KAFKA, Franz. Contos, fábulas e aforismos. Tradução Ênio Silveira. Rio de Janeiro: Civilização Brasileira, 1993.

KAFKA, Franz. Cartas aos meus amigos. Tradução Osvaldo da Purificação. São Paulo: Nova Época, [s.d]

KONDER, Leandro. Kafka vida e obra. Rio de Janeiro: José Alvaro, 1966

LACAN, Jacques. Livro1- O seminário: os escritos técnicos de Freud (1953-1954). Tradução Betty Milan. Rio de Janeiro: Zahar 1983.

LACAN, Jacques. Livro 7 - 0 seminário: a ética da psicanálise (1959-1960). Tradução A. Quinet. Rio de Janeiro: Zahar, 1988.

EMAIRE, Gerard-George. Kafka biografia. Tradução Júlia da Rosa Simões. Porto Alegre: L\&PM, 2006.

PAWEL, Ernest. O pesadelo da razão: uma biografia de Franz Kafka. Tradução Vera Ribeiro. Rio de Janeiro: Imago, 1986.
SITES

DIAMANT, Dora. Minha vida com Franz Kafka: parte I. Tradução de Francisco Merçon. A Palavra, Alegre, ES, n. 170, set. 2011. (Coluna Pensar por escrito, p. 14). Disponível em: < http:// pensarporescrito.tumblr.com/post/11672686294>. Acesso em 19 fev. 2013

DIAMANT, Dora. Minha vida com Franz Kafka: parte III. Tradução de Francisco Merçon. A Palavra, Alegre, ES, n. 172, nov. 2011. Coluna Pensar por escrito, p. 14). Disponível em: <http:// pensarporescrito.tumblr.com/post/14212743105> . Acesso em: 19 fev. 2013. 